\title{
ESTIMATION OF ELECTRON TEMPERATURE IN ATMOSPHERIC PRESSURE DIELECTRIC BARRIER DISCHARGE USING LINE INTENSITY RATIO METHOD
}

\author{
${ }^{1,2}$ R. Shrestha, ${ }^{3}$ R. B. Tyata, ${ }^{1}$ D. P. Subedi ${ }^{*}$ \\ ${ }^{1}$ Department of Natural Science, Kathmandu University, Dhulikhel, Nepal \\ ${ }^{2}$ Department of physics, Napal Banepa Polytechnic College, Kavre, Nepal \\ ${ }^{3}$ Department of Electrical, Khwopa College of Engineering, Libali-2, Bhaktapur, Nepal \\ *Corresponding author: deepaksubedi2001@ yahoo.com \\ Received 17 June, 2012; Revised 29 September, 2012
}

\begin{abstract}
Dielectric Barrier Discharge was produced by applying high voltage AC source of frequency $(10-30 \mathrm{KHz})$ and potential difference of $(0-20) \mathrm{kV}$ across two parallel plate electrodes with glass as dielectric barrier. Optical emission spectroscopy was used for the characterization of the discharge produced at atmospheric pressure. The emission spectra in the range of $200 \mathrm{~nm}$ to $850 \mathrm{~nm}$ have been analyzed to estimate the electron temperature by line intensity ratio method. The results showed that the electron temperature is about $0.9 \mathrm{eV}$.
\end{abstract}

\section{INTRODUCTION:}

Atmospheric pressure dielectric barrier discharges (DBDs) are non thermal and non equilibrium plasmas [1]. These non-equilibrium plasmas have been widely studied for several emerging applications such as; surface and material processing, biological and chemical decontamination of media, light source, absorption and reflection of electromagnetic radiation and synthesis of nanomaterials. This process can be improved by a better understanding of basic plasma phenomena and by knowing its properties. The plasma properties depend on several parameters, mainly, the geometry of the electrodes, type of the dielectric barrier, cooling system, excitation frequency, power injected and gas composition [2, 3].

The electron density and electron temperature are most fundamental parameter in gas discharges and plays very important role in understanding the discharge physics and optimization of the operation of plasma $[4,5]$. Different methods are available to measure the electron density and electron temperature of which the most commonly used are Langmuir probe, microwave interferometer, Laser Thomson Scattering and optical emission spectroscopy (OES) [6].

In atmospheric-pressure discharge, both the probe and the microwave-based methods are difficult to use due to the small plasma dimension and strong collision process. The OES based technique is suitable for measurement of electron density and electron temperature. To measure electron temperature line intensity ratio method is used, in which the intensity ratio of emission lines is related to electron temperature and electron density [7, 8, 9 ].

Another method involves the investigation of the stark broadening of emission lines profiles. Techniques based on optical emission are clearly non-invasive, require only moderate spectroscopic equipment, are easy to implement and measurement are usually fast $[10,11]$. 
In this paper measurement of the electron temperature in filamentary DBD in argon at atmospheric pressure by line intensity ratio method is presented.

\section{EXPERIMENTAL}

The experimental arrangement is shown in Fig. 1. The system consists of two parallel discs of brass, $10 \mathrm{~mm}$ thick and $50 \mathrm{~mm}$ in diameter. The glass plate $1.2 \mathrm{~mm}$ thick was used as dielectric barrier between the two electrodes. A high voltage AC source (0-20) kV and frequency (10-30) $\mathrm{kHz}$ is applied to electrodes.

The whole apparatus is enclosed in cylindrical chamber and argon passed into it. The argon flow rate is maintained at $2 \mathrm{l} / \mathrm{min}$. The amplitude of applied voltage was measured by high voltage probe (Tektronix TDS2002). The optical spectra were recorded by Linear Array Spectrometer VS140

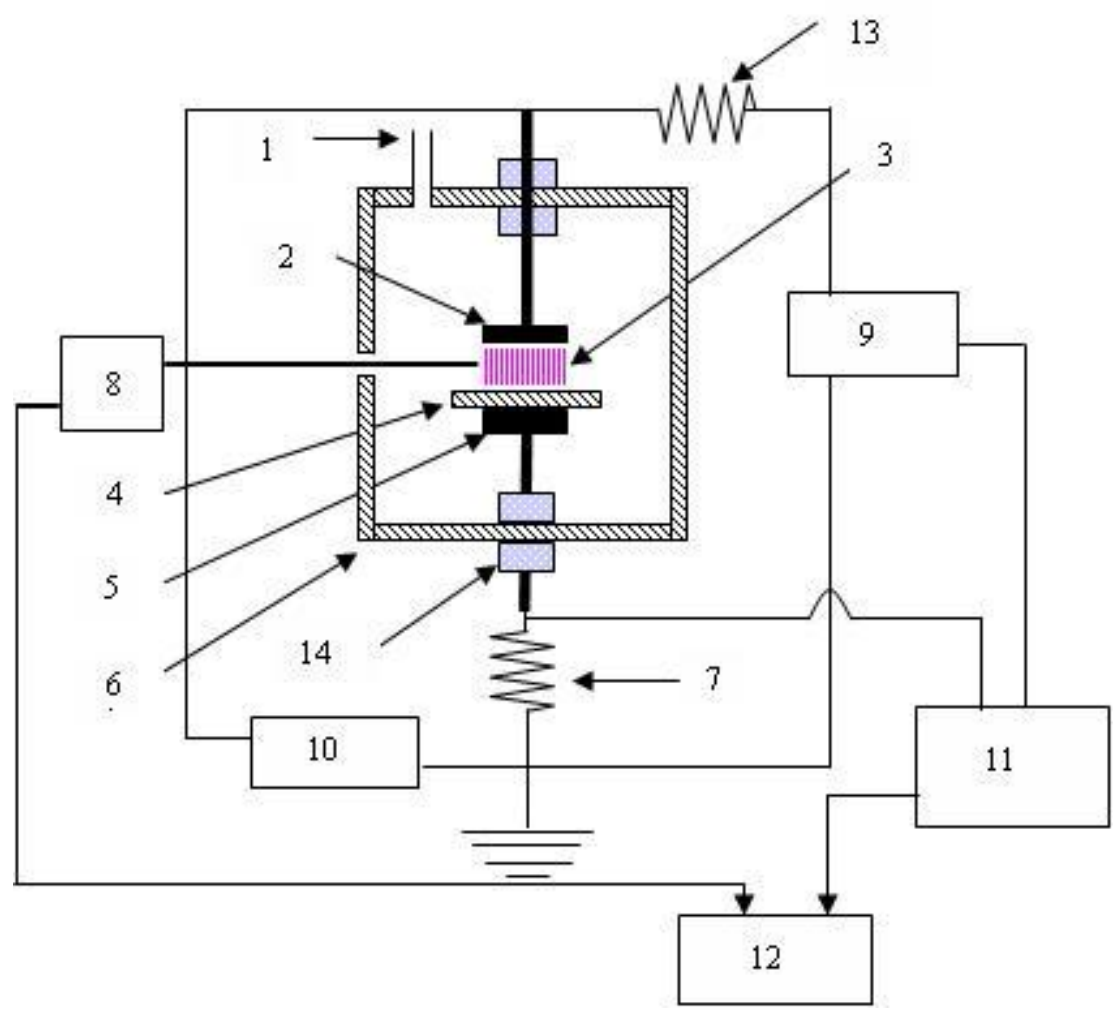

Fig. 1 Experimental arrangement for the diagnostics of the discharge. 1- Gas inlet, 2- Circular parallel plate electrode, 3- Discharge , 4- Glass plate, 5-Grounded electrode, 6- Plasma reactor, 7- Resistance $10 \mathrm{k} \Omega$, 8- Linear Array Spectrometer VS140, 9- Voltage probe, 10- Power supply 11-Oscilloscope, 12-Computer, 13- Resistance 10 $\mathrm{M} \Omega, \quad 14-$ Teflon screw.

\section{RESULTS AND DISSCUSSION}

Fig. 2, 3 and 4 show the optical emission spectra (OES) from the discharge between $250 \mathrm{~nm}$ to $850 \mathrm{~nm}$ at $3 \mathrm{~mm}$ electrode gap. The applied voltage, discharge current and spectrum are simultaneously measured and analyzed for determination of electron temperature. Four suitable 
lines (two for Ar-I and two for Ar-II are chosen and electron temperatures is estimated using the lines intensity ratio method.

For the measurement of electron temperature, following equation is used,

$$
\frac{R_{1}}{R_{2}}=\frac{I_{1} / I_{2}}{I_{3} / I_{4}}=\left(\frac{A_{p q}}{A_{r s}}\right)\left(\frac{g_{p}}{g_{r}}\right)\left(\frac{\lambda_{r s}}{\lambda_{p q}}\right)\left(\frac{A_{u v}}{A_{x y}}\right)\left(\frac{g_{u}}{g_{x}}\right)\left(\frac{\lambda_{x y}}{\lambda_{u v}}\right) \operatorname{Exp}\left[-\frac{E_{p}-E_{r}-E_{x}+E_{u}}{K T_{e}}\right]
$$

where $R$ is the ratio of intensity of two lines, $I$ is the intensity of spectral lines, $A_{i j}$ is the transition probability of the transition $\mathrm{i} \rightarrow \mathrm{j}$, [5].

$g_{i}$ - The statistical weight of the upper level,

$E_{i}$ - energy of the upper level,

$T_{e}$ - electron temperature. $\lambda$ - wave length of the radiation,

$K$ - Boltzmann constant,

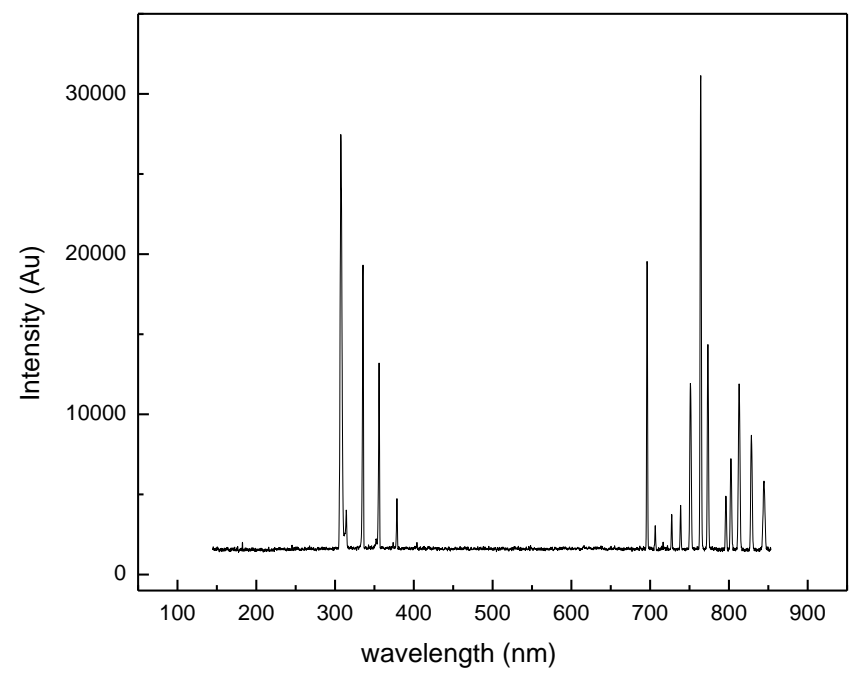

Fig. 2 Optical emission lines of atmospheric pressure discharge produced in Argon. 


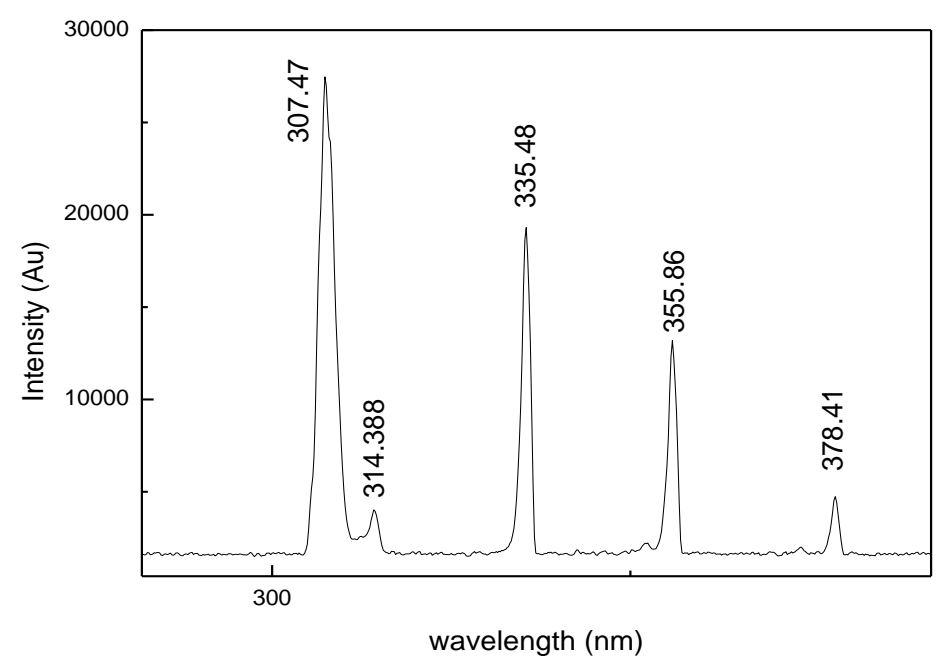

Fig. 3 Ar lines obtained from the APGD in the range of $200 \mathrm{~nm}$ to $450 \mathrm{~nm}$

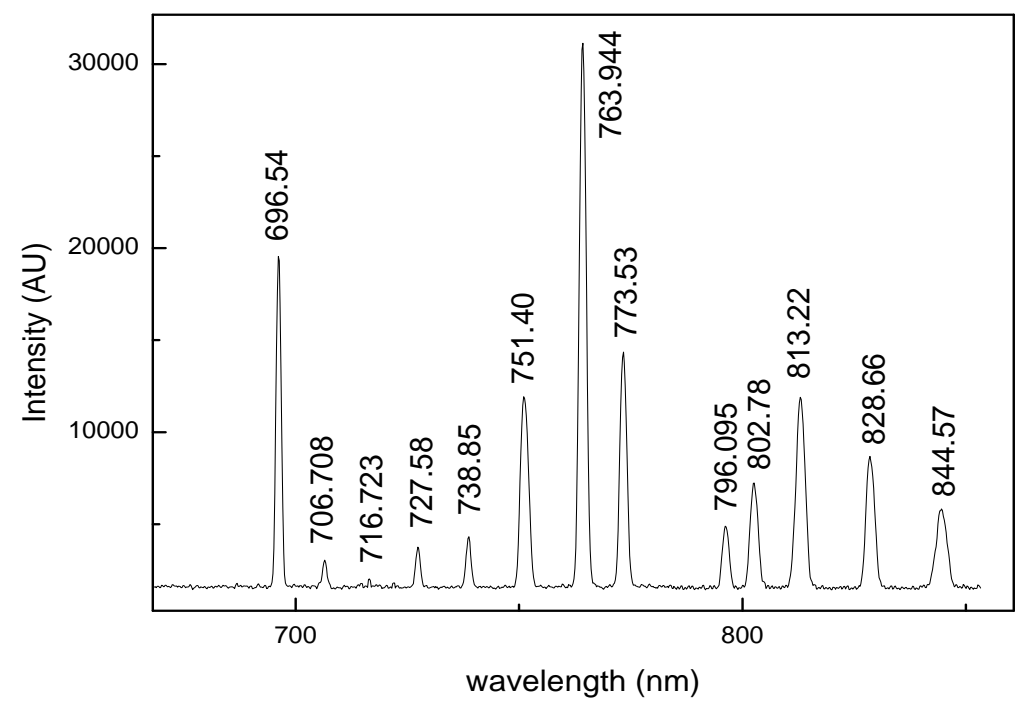

Fig. 4 Ar lines obtained from the APGD in the range of $650 \mathrm{~nm}$ to $850 \mathrm{~nm}$

Considering two Ar I lines of wavelength $696.54 \mathrm{~nm}$, and $751.034 \mathrm{~nm}$ and two Ar II lines with wavelength $314.13 \mathrm{~nm}$ and $378.75 \mathrm{~nm}$ we get,
$\operatorname{ArI}(696.54 \mathrm{~nm})$
$A_{p q}=6.39 \times 10^{6}$
$g_{p}=5$
$E_{p}=11.564$
$\operatorname{ArI}(751.034 \mathrm{~nm}), \quad A_{r s}=4.02 \times 10^{7}$
$g_{r}=3$
$E_{r}=11.636$
ArII $(314.13 \mathrm{~nm})$,
$A_{x y}=5.20 \times 10^{7}$
$g_{x}=6$
$E_{x}=19.249$ 


$$
\text { ArII }(378.75 \mathrm{~nm}), \quad A_{u v}=105 \times 10^{6} \quad g_{u}=8 \quad E_{u}=16.797
$$

Using the above data in equation (1), we obtain $\frac{R_{1}}{R_{2}}=1.13941 \times 10^{-2} \exp \left[\frac{2.5225}{K T_{e}}\right]$

Table 1: Electron temperature and corresponding intensity ratio

\begin{tabular}{|c|c|}
\hline Electron temperature & $\mathbf{R}_{\mathbf{1}} / \mathbf{R}_{\mathbf{2}}$ \\
\hline 0.25 & 274.600 \\
\hline 0.50 & 1.769 \\
\hline 0.75 & 0.322 \\
\hline 1.00 & 0.142 \\
\hline
\end{tabular}

Table 2: Different argon lines with wavelength and intensity obtained from the recorded OES data.

\begin{tabular}{|c|c|c|c|}
\hline Lines & wavelength & Intensity (a.u) & Ratio \\
\hline ArI & 696.54 & 19687.32 & $\mathrm{I}_{1}$ \\
\hline ArI & 751.034 & 11945.13 & $\mathrm{I}_{2}$ \\
\hline ArII & 314.13 & 3897.21 & $\mathrm{I}_{3}$ \\
\hline ArII & 378.75 & 4681.67 & $\mathrm{I}_{4}$ \\
\hline
\end{tabular}

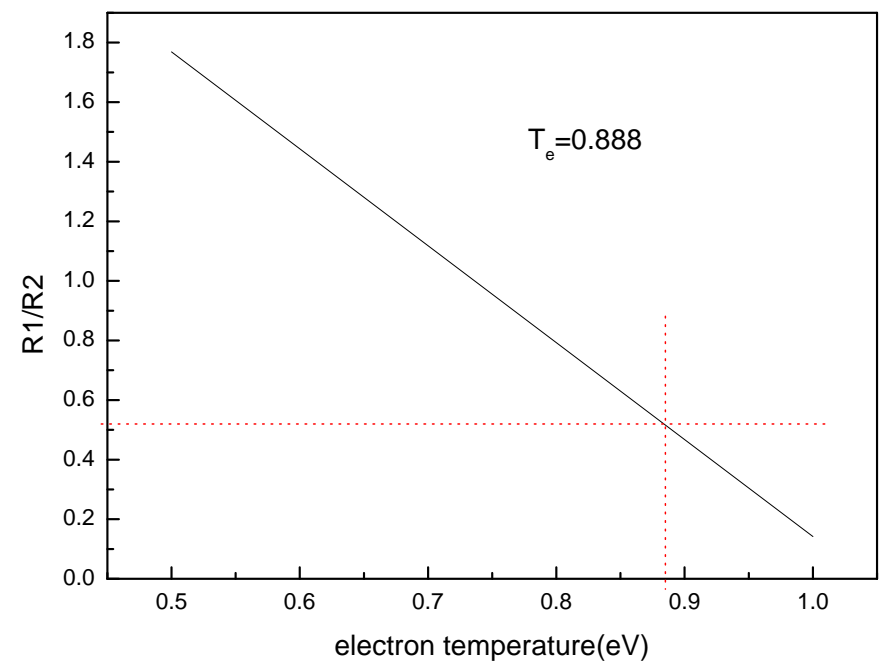

Fig. 5 Plot of $R_{1} / R_{2}$ as a function of $T_{e}$

Fig. 5 is the graph plotted between $T_{e}$ and $R_{1} / R_{2}$ and used to determine the electron temperature by using value of $R_{1} / R_{2}$ obtained from observation. From the observation, $R_{1} / R_{2}=0.5051$ which corresponds to electron temperature $0.888 \mathrm{eV}$. This result is in good agreement with the results reported in previous work. 


\section{CONCLUSION}

The spectral line shape analysis is a reliable and non perturbing method for determining the electron temperature in argon at atmospheric pressure dielectric barrier discharge. The electron temperature is determined by line intensity ratio method and is to be about $0.9 \mathrm{eV}$

\section{REFFERENCES}

1. Becker K H, Kogelschatz U, K H Schoenbach \& Barker R J, Non-equilibrium Air Plasma at Atmospheric pressure. IOP, University of reading, Berkshir, (2005).

2. Lonascut-Nedelcescu A, Carlone C, Kogelschath U, Gravelle D V and Boulos M I, Calculation of the gas temperature in through flow atmospheric pressure dielectric barrier discharge torch by spectral line shape analysis. J Phy D; Appl Phys,103, (2008).

3. Noriyasu O, Abdur R M, Hiroshi U, Shuchi T \& Yoshihiko U, Validity of electron temperature measurement by using Boltzman plot method in radio frequency inductive discharge in the atmospheric pressure range. Plasma and fusion research, 1, 028 (2006).

4. Zhu X M, Pu Y K, Balcon N \& Baswell R, Measurement of the electron density in atmospheric pressure low temperature argon discharge by line ratio method of optical emission spectroscopy. J Phys D; Appl Phys, 42 - 142003 (2009).

5. Chen F F, Introduction to plasma physics and controlled fusion $2^{\text {nd }} e d$. New York (1984).

6. Goktas H, Demir A, Kacar E, Hegazy H, Turan R, Oke G \& Seyhan A, Spectroscopic measurement of electron Temperature and electron density in electron beam plasma generator based on collision radiative model. Spectroscopy letters, 40, 183-192, (2007).

7. Balcon N, Aanesland A, \& Boswell R, Pulsed RF discharge glow and filamentary mode at atmospheric pressure in argon. Plasma Source .Sci. Technol., 25-16217 (2007).

8 Dong L, Yiyan Qi, Zengchao Zhao \& Yonghui Li, Electron density of an individual micro discharge channel in patterns in a dielectric barrier discharge at atmospheric pressure. Plasma source Sci. Technol. 17 (2008).

9. Griem H R, Spectral line broadening by plasma. Academic, New York (1974).

10. Hum Kim J, Ho Choi Y, \& Hwang Y S, Electron density and electron temperature measurement method by using emission spectroscopy in atmospheric pressure nonequilibrium nitrogen. Physics of plasmas, 13-093501 (2006).

11. Zhu X M, Wen-Cong C \& Pu Y K, Gas temperature, electron density and electron temperature measurement in a microwave excited micro-plasma. J Phys D; Appl Phys, 41-105212 (2008). 